\title{
Impactos Socioeconômicos das Plantações Florestais no Niassa, Moçambique
}

\author{
Teresa Guila Nube ${ }^{1}$, Anadalvo Santos Juazeiro dos Santos ${ }^{2}$, \\ Romano Timofeiczyk Junior ${ }^{2 *}$, Ivan Crespo Silva ${ }^{3}$

\begin{abstract}
${ }^{1}$ Ministério da Agricultura, Direção Nacional de Terras e Florestas, Maputo, Moçambique. ${ }^{2}$ Departamento de Economia Rural e Extensão, Universidade Federal do Paraná - UFPR, Curitiba/PR, Brasil. ${ }^{3}$ Departamento de Ciências Florestais, Universidade Federal do Paraná - UFPR, Curitiba/PR, Brasil.
\end{abstract}

\section{Resumo}

O objetivo deste trabalho foi avaliar os impactos socioeconômicos das plantações florestais nas comunidades da província do Niassa, Moçambique. Foram realizadas entrevistas semiestruturadas com 423 chefes de famílias residentes no entorno das empresas florestais. Os dados foram obtidos mediante aplicação de questionários direcionados aos gestores das empresas florestais e membros do governo, e analisados com uso de estatística descritiva, tendo-se considerado o período anterior e posterior à instalação das empresas florestais. Os resultados evidenciaram melhorias de condições de vida das famílias, sobretudo aquelas que têm emprego nas empresas florestais. Porém, a presença das empresas florestais reduziu a dependência e a acessibilidade das famílias em relação aos recursos florestais devido ao aumento das distâncias das fontes de obtenção.

Palavras-chave: Empresas florestais, plantações em Moçambique, comunidades rurais.

\section{Socioeconomic Impacts of Forest Plantations in Niassa, Mozambique}

\begin{abstract}
The aim of this research was to assess the socioeconomic impacts of forest plantations in the householders' livelihood in the Niassa province communities, northern Mozambique. Were conducted semi-structured interviews with 423 households in communities around the forest companies, forest plantation managers and the govern local senior members of the govern. The data collected were analyzed using descriptive statistics, considering the period before and after implementation of forestry companies. The results showed improvements in the livelihood of the householders, especially those who are employed in forestry companies. The presence of forestry companies reduced dependence and accessibility of families in relation to forest resources due to increasing distances from the sources of production.
\end{abstract}

Keywords: Forestry companies, plantations in Mozambique, rural communities. 


\section{INTRODUÇÃO}

Moçambique está localizado na África Austral, possui uma superfície total de $799.380 \mathrm{~km}^{2}$ e uma população estimada de 23,7 milhões de habitantes, dos quais cerca de $80 \%$ dependem dos recursos florestais para sua subsistência. A população moçambicana cresce em média 2,8\% ao ano e apresenta altos índices de analfabetismo, com $55 \%$ das pessoas vivendo abaixo da linha da pobreza, onde a incidência da pobreza é muito maior nas zonas rurais.

A agricultura é o setor fundamental para a economia do país, onde $85 \%$ da população depende dela para seu sustento (PNUD, 2012). Como consequência, cerca de 220 mil hectares de florestas perdem-se anualmente pelo desmatamento, tornando Moçambique um dos países com alta taxa de desmatamento, causado principalmente pela extração de madeira, lenha e fabricação de carvão, queimadas descontroladas, agricultura itinerante ou abertura de pequenas áreas de machambas dentro de florestas (Sitoe et al., 2012).

Para reduzir a pressão sobre a floresta nativa, o governo de Moçambique decidiu em meados da década de 2000, através da apresentação do documento da Estratégia Nacional de Reflorestamento, promover as plantações florestais com espécies de rápido crescimento. Esta decisão começou a catalisar interesse das empresas privadas estrangeiras em investir em silvicultura. O grande atrativo para as empresas são as condições edafoclimáticas favoráveis para o desenvolvimento da silvicultura intensiva aliada à disponibilidade de terra. Estima-se que existem aproximadamente 7 milhões de hectares de terra aptas para plantios florestais, sendo a província do Niassa que detém maior área, com 2,4 milhões de hectares.

A terra é o grande atrativo para os investimentos florestais, não somente pela sua disponibilidade mas também pelo fato de que, segundo a legislação moçambicana, a terra pertence ao Estado e as comunidades rurais têm o direito de uso e aproveitamento das mesmas (Oram, 2010; Serra \& Chicue, 2005). Normalmente as terras disponibilizadas pelas comunidades rurais para o reflorestamento são improdutivas para a prática da agricultura e com poucas ou nenhuma espécie de valor madeireiro (Landry, 2009). A zona norte de Moçambique é predominantemente coberta pelas savanas do miombo (Marzoli, 2007), que são florestas com um alto índice de diversidade de espécies, mas com baixo índice de valor econômico (White, 1983, Gauslaa, 1989). Esse fato contribui para que o valor de Direito de Uso e Aproveitamento da Terra (DUAT), que é pago pelas empresas, seja muito baixo.

Com a grande procura de terras pelas empresas florestais para o estabelecimento de plantios com fins industriais e comerciais na província do Niassa, as comunidades locais providenciaram extensas áreas na expectativa de benefícios de emprego nessas empresas. Entretanto, existe pouca informação sobre os benefícios das empresas florestais para as comunidades, porém há necessidade de saber se os custos de abdicação das terras em troca de emprego nas empresas florestais são compensatórios. Por outro lado, existe um reconhecimento de que a maior parte da mão de obra utilizada pelas empresas florestais provém das comunidades locais, porém, informações sobre a influência dessas empresas na melhoria do nível de vida das referidas comunidades é quase inexistente.

Dentro desse contexto, este trabalho teve como objetivo principal avaliar os impactos socioeconômicos das plantações florestais em três distritos na província do Niassa. Os objetivos específicos procuraram caracterizar sob ponto de vista socioeconômico a situação das famílias antes e depois da instalação das empresas florestais; diagnosticar a situação socioeconômica das famílias com e sem emprego nas empresas florestais, e demonstrar os impactos das diferenças salariais no nível de vida das famílias.

\section{MATERIAL E MÉTODOS}

\subsection{Descrição do local do estudo}

O estudo foi realizado na província do Niassa, localizada no noroeste de Moçambique, com uma área de 129 mil km² e constituída por 16 distritos (Figura 1).

A área de estudo foi identificada com base na existência dos seguintes fatores: (i) empresa florestal, (ii) população residente na área onde se encontram as plantações e (iii) pessoas da comunidade que trabalham nas empresas florestais. Foram selecionados os distritos de Lichinga, Lago e Sanga, regiões onde operam as empresas Floresta de Niassa, Chikweti Forest of Niassa e Niassa Green Resources, SA, respectivamente. 


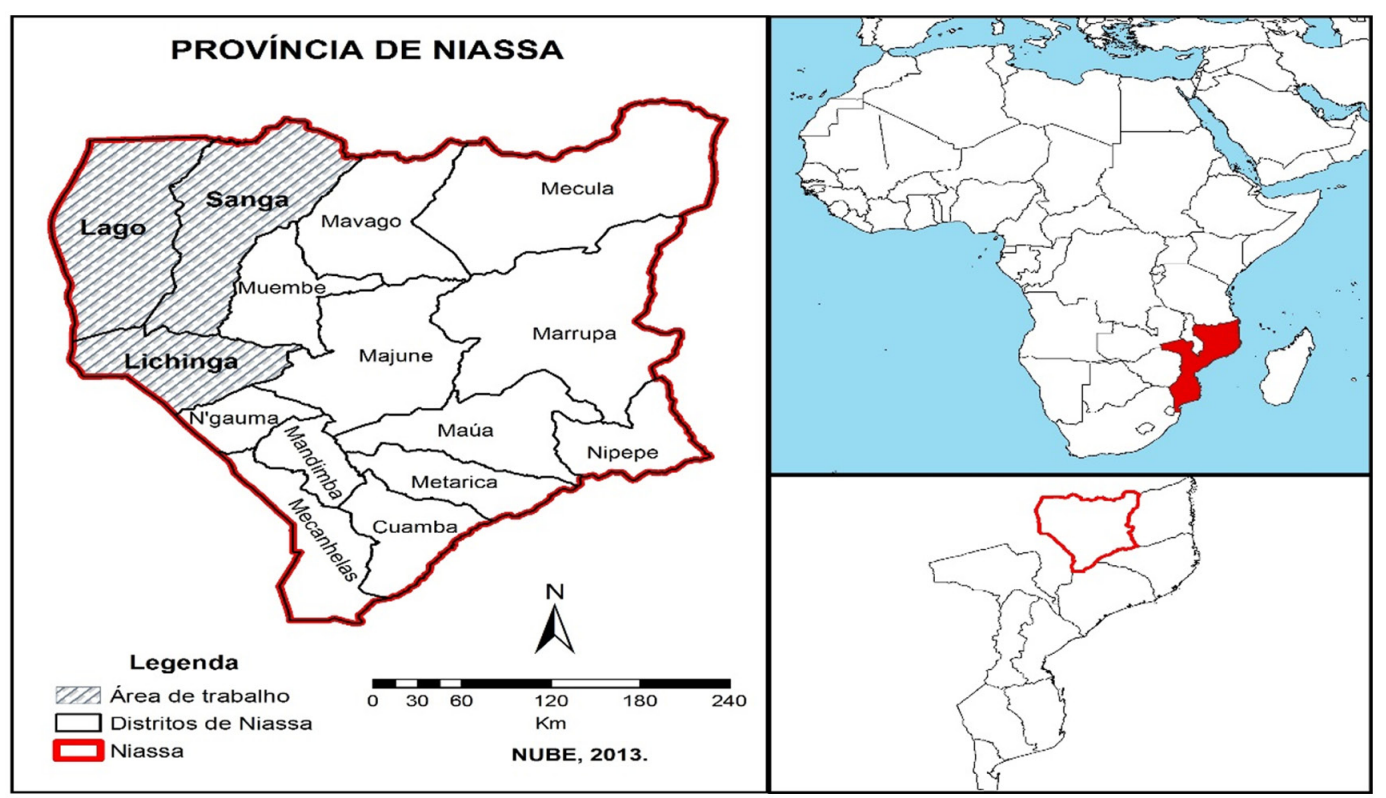

Figura 1. Localização da área de estudo.

Figure 1. Localization of the study area.

Segundo a classificação de Köppen, o clima da região é tropical úmido com verões quentes e chuvosos, invernos secos e frios ${ }^{\mathrm{a}} \mathrm{a}$. A precipitação média anual varia de $1.200 \mathrm{a} 1.350 \mathrm{~mm}$. As temperaturas médias anuais são de 21 a $23^{\circ} \mathrm{C}$. A formação florestal nativa predominante na área é miombo decíduo seco e tardio. O miombo distingue-se de outras formações florestais e das savanas africanas pela predominância de três espécies da família Fabaceae, subfamília Caesalpinoideae, particularmente dos gêneros Brachystegia, Julbernardia e Isoberlinia (Frost, 1996; Ribeiro et al., 2008).

O miombo constitui o tipo de vegetação mais importante da África Austral, cobrindo uma área de cerca de 2,7 milhões de $\mathrm{km}^{2}$ em sete países, nomeadamente: Angola, Congo RD, Malawi, Moçambique, Tanzânia, Zâmbia e Zimbábue, que fazem parte da lista dos países mais pobres dos do mundo (Chidumayo, 1993; Campbell et al., 1996; Dewees et al., 2010).

\subsection{Coleta de dados}

Os dados primários foram obtidos mediante aplicação de questionários direcionados aos gestores das empresas florestais e membros do governo, entrevistas

\footnotetext{
${ }^{a}$ Exceto o distrito de Lichinga, que é influenciado pela altitude.
}

semiestruturadas direcionadas aos chefes dos agregados familiares com base em uma amostragem. Segundo Gil (2007), a entrevista, além de poder ser aplicada a um grande número de pessoas, permite colher informação de pessoas que não sabem ler nem escrever, visto que permite auxílio ao entrevistado e análise do seu comportamento não verbal. A amostragem conduzida foi de forma aleatória e toda a população teve a mesma probabilidade de ser selecionada. A unidade de amostragem é o agregado familiar.

Para o efeito de amostragem, usou-se como base a população, assumindo que esta é homogênea em termos de atividades de produção e de renda. O tamanho da amostra foi calculado com base na fórmula de Rea \& Parker (1997), que leva em consideração o erro amostral, o tamanho da população e o grau de confiança de $95 \%$ (Equação 1).

$n=\frac{Z^{2} \alpha^{*}(0,25) * N}{Z^{2} \alpha^{*}(0,25)+(N-1) * C^{2} p}$

Em que:

n - tamanho da amostra calculada

$\mathrm{Cp}$ - intervalo de confiança em termos de proporção Za - proporções da variação do nível de confiança $(95 \%, 1.96)$

$\mathrm{N}$ - número de famílias 
A partir da fórmula sugerida por Rea \& Parker (1997), foi calculado o tamanho total da amostra $(\mathrm{n}=365)$ com base no número total da população $(\mathrm{N}=6316)$. A disponibilidade de recursos financeiros e as condições técnicas encontradas no campo permitiram entrevistar 432 chefes de famílias, número relativamente superior ao tamanho da amostra calculado. Assim, com o tamanho da amostra utilizado, o erro padrão é mínimo para a precisão desejada, o que significa que os dados têm valor estatístico.

Os dados secundários, necessários para complementar a informação dos entrevistados, como para confrontar com a informação obtida no campo, foram obtidos das pesquisas bibliográficas em livros encontrados em bibliotecas, nas empresas florestais e em documentos providenciados pelas autoridades governamentais, bem como da pesquisa em bibliotecas virtuais, repositórios e bases de dados.

Este trabalho tem carácter exploratório e descritivo, portanto, para o processamento e análise de dados recorreu à estatística descritiva. Os dados coletados foram processados no pacote Excel e programa SPSS. 18 (Statical Package for Social Science), em função do requerimento dos programas e das análises a serem feitas.

\subsection{Análise de dados}

Para a análise das diferenças entre as classes socioeconômicas, foi usado o critério de avaliação de renda em vigor no Brasil (ASSOCIAÇÃO BRASILEIRA DE EMPRESAS DE PESQUISA - ABEP, 2012). Justifica-se a adequação deste critério à realidade moçambicana, pelo fato de os dados (tipos de bens) coletados se adequarem facilmente ao uso do critério.

Para a classificação da população em classes econômicas de posses de bens, usou-se o critério ABEP (2012), que ajudou definir o nível socioeconômico dos chefes dos agregados familiares, residentes nos diferentes distritos. Assim, os pesos dos diferentes bens que os chefes dos agregados familiares possuem foram ajustados à realidade moçambicana, tomando como base o critério Brasil. Aos bens de difícil aquisição, devido aos preços elevados, foram também atribuídos maior pontuação, sucessivamente, conforme mostra a Tabela 1.

Na sequência, foram definidas três classes sociais a partir dos pesos atribuídos aos bens na Tabela 1, que foram usados para definir as classes sociais na Tabela 2.

Foi aplicado o teste qui-quadrado para testar as seguintes hipóteses nulas de pesquisa:

$\mathrm{H} 1_{0}=$ Não existem diferenças significativas na posse de bens entre os chefes de agregados familiares que trabalham e os que não trabalham em empresas florestais; $\mathrm{H} 2_{0}=$ A posse de bens não é determinada pelo nível salarial.

A fim de analisar as diferenças salariais dos chefes dos agregados familiares que trabalham em empresas florestais, fez-se uma classificação dos salários baseada no salário mínimo estipulado pelo Governo para o setor agrícola, situando-se em 2.300,00 meticais (US\$ 83). Todos os que recebem um valor abaixo do salário mínimo foram classificados com o nível salarial baixo, e acima do salário mínimo nível salarial alto, e os restantes classificados como de nível salarial médio.

Tabela 1. Pesos atribuídos aos bens que os chefes dos agregados familiares possuem.

Table 1. High score assigned to goods that the households own.

\begin{tabular}{lclclc}
\multicolumn{1}{c}{ DESIGNAÇÃO } & PESOS & DESIGNAÇÃO & PESOS & DESIGNAÇÃO & PESOS \\
Casa melhorada & 8 & Gado & 5 & Rádio & 2 \\
Machamba & 7 & Bicicleta & 4 & Conta bancária & 1 \\
Motorizada & 6 & Telemóvel & 3 & Aves & 1 \\
\hline
\end{tabular}

Tabela 2. Definição de classes sociais.

Table 2. Definition of classes.

\begin{tabular}{ccc} 
CLASSES & DESIGNAÇÃO & PONTOS \\
Média & A1 & $>18,0-37,0$ \\
Pobre & A2 & $>10,0-18,0$ \\
Paupérrima & B & $0,0-10,0$ \\
\hline
\end{tabular}




\section{RESULTADOS E DISCUSSÃO}

\subsection{Caracterização sociodemográfica e econômica das famílias}

O número total de famílias no entorno das empresas florestais é de 6.361 agregados. Do estudo foram feitas entrevistas com 432 chefes de agregados, dos quais 328 (74\%) são chefiadas por homens e 104 (26\%) por mulheres. A faixa etária com maior representatividade foi a dos adultos com idade igual ou superior a 40 anos ocupando 52\% da amostra. Em relação ao nível de escolaridade, $37 \%$ chefes dos agregados familiares foram identificados como sendo analfabetos e $63 \%$ frequentaram a escola, sendo que a maioria frequentou até apenas $3^{\text {a }}$ classe e não sabem ler e escrever. Landry (2009) também encontrou resultados semelhantes aos colhidos neste trabalho, nos distritos de Lago e Sanga.

\subsection{Origem da renda}

Atualmente, as principais atividades das famílias em torno das empresas florestais são produção agrícola e trabalho formal. Antes da instalação das empresas florestais, a adoção da agricultura era de $88,2 \%$ e atualmente é de $62,3 \%$. Esta situação justifica-se pela presença dos projetos florestais que proporcionam emprego, com as pessoas abdicando da agricultura como atividade principal e passando para o emprego remunerado. Falcão (2009), Salomão \& Matose (2007), Enosse et al. (2009) e Landry (2009) afirmam que, em Moçambique, $80 \%$ da população pratica a atividade agrícola como a principal fonte de renda

A comercialização de produtos agrícolas e florestais, trabalhos domésticos, caça, trabalhos em empresas florestais, são as principais atividades praticadas pelos chefes dos agregados familiares nas regiões estudadas. Esperava-se que, com a presença das empresas florestais, ocorresse uma mudanças das atividades praticadas pelos chefes dos agregados familiares, o que não foi verificado, provavelmente devido ao reduzido número dos chefes de agregados familiares que trabalham em empresas florestais (aproximadamente 48\%).

\subsection{Produtos agrícolas cultivados}

As principais culturas agrícolas produzidas pelas famílias na área de estudo são milho (Zea mays L), feijão-manteiga (Phaseolus vulgaris, L.) e batata-reno
(Solanum tuberosum L.). O milho é produzido por 100\% das famílias e base de alimentação, e $98 \%$ das famílias cultivam o feijão-manteiga, sendo esta cultura de grande importância para o sustento local e para o incremento da renda (Figura 2).

Os resultados obtidos nesta pesquisa confirmam as assertivas de Enosse et al. (2009) e Landry (2009) sobre as principais culturas agrícolas produzidas na região. Observa-se que não houve nenhuma mudança na proporção e nem nas variedades de culturas produzidas antes e depois da implantação das empresas florestais.

\subsection{Produtos florestais coletados pelas famílias}

$\mathrm{Na}$ Figura 3, apresentam-se os principais produtos florestais coletados pelos chefes dos agregados familiares. Observa-se que houve um decréscimo na procura desses produtos com a implantação das empresas florestais, com exceção da lenha. Isso deve-se ao fato

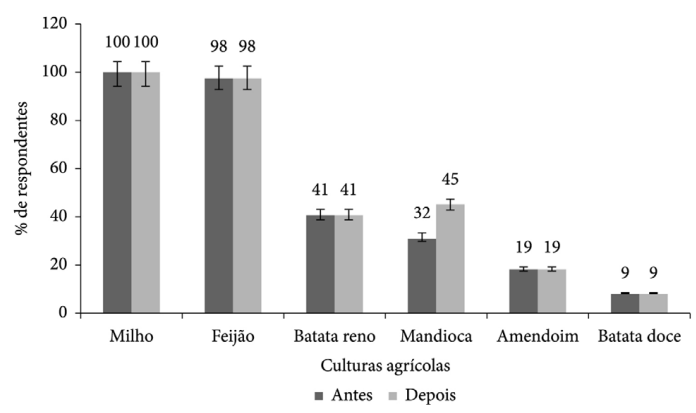

Figura 2. Principais culturas agrícolas produzidas pelos chefes dos agregados familiares nos diferentes distritos estudados.

Figure 2. Main agricultural crops produced by the households in the different districts Sampled.

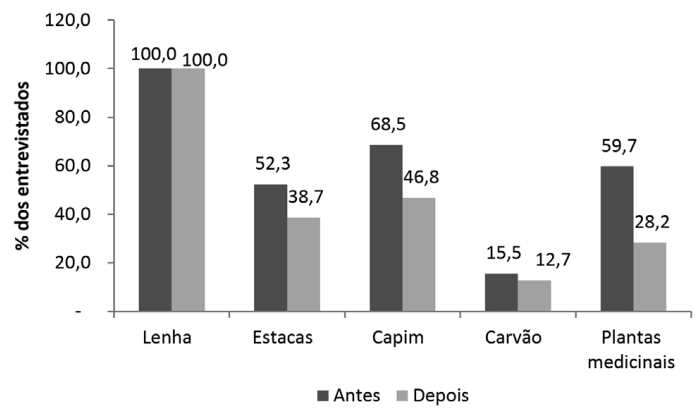

Figura 3. Principais produtos florestais coletados pelos chefes dos agregados familiares.

Figure 3. Main Forest Products collected by the householders. 
de os chefes familiares possuírem uma fonte de renda capaz de adquirir outros produtos substitutos mais duráveis, tais como casas de alvenaria, e terem acessos às unidades sanitárias.

Com a presença das empresas florestais, foi verificada redução na produção de carvão vegetal. Este fato está associado ao emprego formal, uma vez que as pessoas trabalhando nas empresas florestais não dispõem de tempo para se dedicarem a esta atividade e, por outro lado, as empresas aumentaram das distâncias para o alcance da matéria-prima para a produção de carvão vegetal devido às restrições impostas às famílias nas áreas ao redor delas.

\subsection{A evolução socioeconômica das famílias antes e depois da instalação das empresas}

Como se pode observar na Figura 4, a presença das empresas florestais propiciou mudanças na vida das comunidades rurais, particularmente em termos de aquisição de bens. Fica evidente que quase todos chefes de famílias que trabalham em empresas florestais aumentaram a aquisição dos bens, sendo a casa melhorada, conta bancária e telefone celular os bens que apresentaram maior variação. As pessoas com emprego formal têm oportunidade de promover melhorias em suas casas, pois a casa melhorada não acarreta custos anuais adicionais, como desembolso na compra de capim. Em Moçambique, a qualidade da habitação de uma família é um indicador aceito para a definição de riqueza, representando maior valor de investimentos em bens duráveis (Moçambique, 2010).

Atualmente verifica-se um crescimento em $37,5 \%$ de famílias na posse de telefones celulares (Figura 4). Esta situação não está diretamente relacionada com a chegada das empresas florestais, mas sim pelo surgimento de novas tecnologias de comunicação e informação.

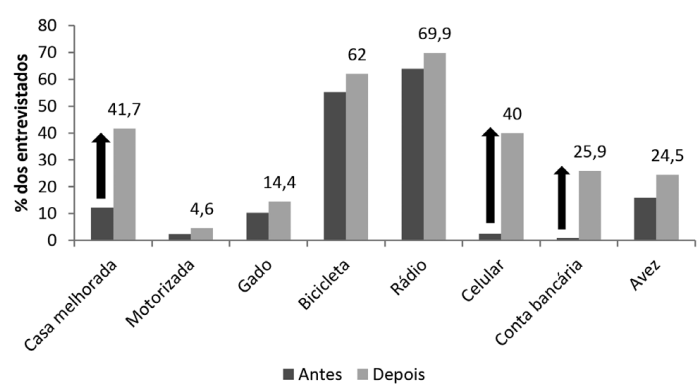

Figura 4. Principais bens das famílias. Figure 4. Major household possessions.
Recentemente, empresas de telefonia móvel estão se estabelecendo nas zonas rurais e disponibilizando o sinal de comunicação. Enosse et al. (2009) relatam que apesar de a rede de telefonia móvel ainda não ser extensiva nos distritos, as pessoas que possuem telefone celular usam quando se deslocam para a capital da província do Niassa ou alguns pontos dos distritos com sinal para se comunicarem com os familiares. O aumento de $1 \%$ para 26\% do número de chefes de agregados familiares com conta bancária deve-se ao fato de as empresas abrirem as contas para todos os funcionários, como forma de garantir segurança no pagamento dos salários.

Com a introdução das empresas florestais, verificou-se um aumento em aproximadamente $23,5 \%$ dos chefes dos agregados de famílias nas classes médias, e uma redução em $30 \%$ na classe paupérrima, indicativo de melhoria do nível de vida nas comunidades rurais (Figura 5). Segundo van Bodegom et al. (2008), em Moçambique, bem como em muitos outros países, existe uma forte concepção de que as empresas florestais ajudaram na redução da pobreza em zonas rurais, pela maximização de uso das terras não produtivas. As plantações florestais também podem ajudar a reduzir a pressão nas florestas nativas e providenciar benefícios ambientais. Garlipp \& Foelkel (2009) relatam que as plantações florestais têm importante papel para mitigar ou reduzir a pobreza, tanto em países em desenvolvimento como em áreas de países desenvolvidos.

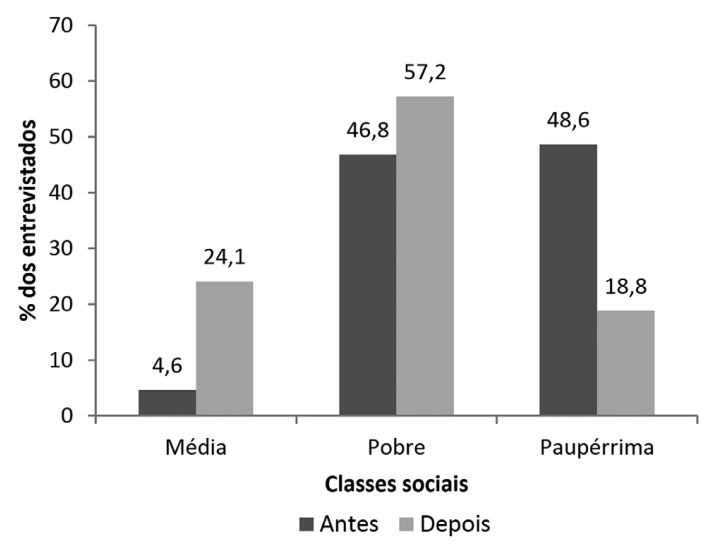

Figura 5. Desempenho das classes sociais-económicas dos chefes de famílias no período anterior e posterior à instalação das empresas florestais.

Figure 5. Performance of socio-economic classes of householders in the period before and after Forest Companies. 
A Tabela 3 apresenta as classes sociais das famílias com e sem emprego nas empresas florestais em cada distrito. Observa em todos os distritos a existência das três classes sociais para as famílias sem emprego. Para as famílias com emprego, a classe social paupérrima deixou de existir, ou seja, nenhuma pessoa com emprego formal pertence a esta classe social. Isto porque os trabalhadores das empresas florestais se beneficiam de emprego e recebem um salário que lhes permite sair da classe paupérrima, uma vez que passam a ter mais recursos financeiros para o consumo de bens.

Observa-se ainda que, para as famílias sem emprego, as classes pobre e paupérrima ocorrem com mais frequência. $\mathrm{O}$ distrito de Sanga se apresenta com maior percentagem (34,9\%) de famílias da classe paupérrima, e Lago se apresenta com maior percentagem $(25,6 \%)$ da classe média. Este cenário revela a condição de vida das famílias sem a intervenção dos projetos florestais.

Em todos os distritos, a classe média encontra-se acima de 30\%, com maior destaque para Lichinga, onde esta classe é maior $60 \%$. Esta situação está relacionada com o fato de Lichinga ser a capital do distrito e os trabalhadores têm mais oportunidades de reinvestir o dinheiro que recebem das empresas florestais e gerar novas rendas.

Para verificar as diferenças estatísticas, com base nos dados observados em campo, foi feito um teste estatístico $\chi \chi^{2}$ para os três distritos, baseando-se na hipótese nula de que não existem diferenças entre as classes de posse de bens nos três distritos. Estatisticamente há evidências significativas para rejeitar a hipótese nula quando comparadas as pessoas que não trabalham em empresas florestais $\left(\alpha=0,049^{*} 10^{-3 * *}\right)$. Este aspecto é relevante entre as classes pobre e paupérrima e isto está relacionado com a renda baixa, variável e instável, quando comparados com os que possuem emprego nas empresas florestais e assim têm renda maior e fixa. Por outro lado, o teste $\chi^{2}$ mostrou que não existem diferenças significativas para refutar a hipótese nula, quando a análise é feita entre os trabalhadores das empresas florestais $\left(\alpha=0,097^{\mathrm{ns}}\right)$.

Observa-se também que a classe paupérrima não existe em todos os distritos, quando comparados aos trabalhadores das empresas florestais. Landry (2009), na sua pesquisa realizada no distrito de Lago, já havia advertido sobre a possibilidade da presença das empresas florestais criarem uma grande defasagem entre ricos e pobres, se todos os chefes de famílias não tivessem as mesmas oportunidades, o que se observa em todas as áreas onde as empresas florestais operam.

\subsection{Impactos das diferenças salariais no nível de vida}

A Tabela 4 apresenta as classes sociais dos trabalhadores dos três distritos e os respectivos níveis salariais. Observa-se que a maioria (52 trabalhadores) auferem salário médio, 45 trabalhadores possuem valor abaixo de um salário mínimo estipulado pelo governo de Moçambique para o setor agrícola, e uma minoria tem um salário alto. Esta situação está associada ao baixo nível de escolaridade das comunidades, uma vez que o salário é pago de acordo a categoria dos trabalhadores, com os de elevado nível de escolaridade auferindo alto salário.

Tabela 3. Classes sociais dos chefes dos agregados familiares com e sem emprego nas empresas por distrito.

Table 3. Householders social classes with and whedought employment.

\begin{tabular}{|c|c|c|c|c|c|c|c|c|c|}
\hline & & & & & TO & & & & \\
\hline & & LIC & GA & & & & & & \\
\hline CLA & DES SOCIAIS & Abs & $\%$ & Abs & $\%$ & Abs & $\%$ & Abs & $\%$ \\
\hline & Média & 6 & 7,4 & 40 & 25,6 & 10 & 12,0 & 56 & 13,0 \\
\hline & Pobre & 62 & 76,5 & 77 & 49,4 & 44 & 53,0 & 183 & 42,4 \\
\hline $\mathrm{SE}$ & Paupérima & 13 & 16,0 & 39 & 25,0 & 29 & 34,9 & 81 & 18,8 \\
\hline & TOTAL & 81 & & 156 & & 83 & & 320 & \\
\hline & Média & 15 & 60,0 & 21 & 42,0 & 12 & 32,4 & 48 & 11,1 \\
\hline $\mathrm{E}$ & Pobre & 10 & 40,0 & 29 & 58,0 & 25 & 67,6 & 64 & 14,8 \\
\hline & TOTAL & 25 & & 50 & & 37 & & 112 & \\
\hline
\end{tabular}

Onde: $\mathrm{N}^{\circ}=$ Números de famílias; $\mathrm{SE}=$ Chefes de famílias sem emprego em empresas florestais; $\mathrm{E}=$ Chefes de famílias com emprego em empresas florestais.

Where: $\mathrm{N}^{\circ}=$ Numbers of householders; $\mathrm{SE}=$ householders whidought employment in forest companies; $\mathrm{E}=$ householders with employment in the forest companies. 
Tabela 4. Classes sociais e níveis salariais dos trabalhadores nos três distritos.

Table 4. Social classes and salary levels in the three districts.

\begin{tabular}{|c|c|c|c|c|c|c|c|c|c|}
\hline \multicolumn{10}{|c|}{ NÍVEL SALARIAL } \\
\hline \multirow{2}{*}{ DISTRITOS } & \multirow{2}{*}{$\begin{array}{l}\text { CLASSES } \\
\text { SOCIAIS }\end{array}$} & \multicolumn{2}{|c|}{ ALTO } & \multicolumn{2}{|c|}{ MÉDIO } & \multicolumn{2}{|c|}{ BAIXO } & \multicolumn{2}{|c|}{ TOTAL } \\
\hline & & Abs & $(\%)$ & Abs & $(\%)$ & Abs & $(\%)$ & Abs & $(\%)$ \\
\hline \multirow{2}{*}{ LICHINGA } & Média & 2 & 13,3 & 4 & 7,7 & 9 & 20 & 15 & 13,4 \\
\hline & Pobre & 0 & 0,0 & 0 & 0,0 & 10 & 22,2 & 10 & 8,9 \\
\hline \multirow{2}{*}{ LAGO } & Média & 8 & 53,3 & 12 & 23,1 & 1 & 2,2 & 21 & 18,8 \\
\hline & Pobre & 0 & 0,0 & 24 & 46,2 & 5 & 11,1 & 29 & 25,9 \\
\hline \multirow{2}{*}{ SANGA } & Média & 4 & 26,7 & 2 & 3,8 & 6 & 13,3 & 12 & 10,7 \\
\hline & Pobre & 1 & 6,7 & 10 & 19,2 & 14 & 31,1 & 25 & 22,3 \\
\hline TOTAL & & 15 & & 52 & & 45 & & 112 & \\
\hline
\end{tabular}

Abs - Valor absoluto.

Abs - Absolute values.

O distrito de Lago é o que se evidencia, apresentando-se com elevada percentagem de trabalhadores $(53,3 \%)$ pertencendo à classe social média com salário alto; por outro lado, tem menor percentagem $(2,2 \%)$ na classe média com salário baixo. O nível salarial predominante nos distritos de Lichinga e Sanga são baixos. O resultado aqui encontrado reforça a constatação anteriormente referida, no que diz respeito à ampliação da classe média das famílias do distrito de Lago.

Em geral, pode-se afirmar que em todos os distritos há uma tendência de os salários altos serem auferidos por uma minoria, e isto está relacionado com elevados níveis de analfabetismo, conforme referido anteriormente. No entanto, pelo teste estatístico qui-quadrado, partindo da hipótese nula de que "a posse de bens não é determinada pelo nivel salarial", constatou-se que para o nível de probabilidade $(\mathrm{P} \leq 0,05)$, se comparado com os valores de alfa calculado $\left(\alpha=0,033^{*} 10^{-8 * *} ; \alpha=0,08^{\star} 10^{-34 * *} \mathrm{e}\right.$ $\alpha=0,011^{\star} 10^{-26 * *}$ ) para os distritos de Lichinga, Lago e Sanga, respectivamente, que estatisticamente não foi encontrada nenhuma evidência suficiente para refutar que a posse de bens está associada ao nível salarial (rejeitou-se a hipótese nula).

\section{CONCLUSÕES}

De acordo com os resultados obtidos na pesquisa, concluiu-se que:

- As empresas florestais aumentaram a distância para o acesso aos recursos florestais, bem como diminuiu a dependência das comunidades em relação estes.
- As empresas florestais trouxeram benefícios para as populações rurais e contribuem para a melhoria da qualidade de vida das famílias, sobretudo aquelas que trabalham nas empresas.

- A instalação das empresas florestais possibilitou o aumento da classe média e a redução da classe social paupérrima.

- De forma geral, observa-se a melhoria das condições dos chefes dos agregados familiares após a implementação das empresas florestais.

\section{STATUS DA SUBMISSÃO}

Recebido: 16 abr. 2013

Aceito: 25 jun. 2015

*AUTOR(ES) PARA CORRESPONDÊNCIA

Romano Timofeiczyk Junior

Departamento de Economia Rural e Extensão, Universidade Federal do Paraná - UFPR, CEP 80420-030, Curitiba, PR, Brasil e-mail: romano.timo@gmail.com

\section{REFERÊNCIAS}

Associação Brasileira de Empresas de Pesquisas - ABEP. Critério de classificação econômica Brasil [online]. 2012 [citado em 2012 jul. 26]. Disponível em: http://www.abep. org/novo/Utils/FileGenerate.ashx?id=19

Campbell B, Frost P, Byron N. Miombo woodlands and their use: overview and key issues. In: Campbell B, editor. The Miombo in transition: woodlands and welfare in Africa. Bogor, Indonesia: CIFOR; 1996. 
Chidumayo EN. Silvicultural characteristics and management of miombo woodland. In: Piearce GD, Gumbo DJ, editores. Proceedings of an International Syposium of the Ecology and Management of Indigenous Forests in Southern Africa; 1992 July 27-29; Victoria Falls. Harare: Zimbabwe Forestry Commission; 1993.

Dewees PA, Campbell BM, Katerere Y, Sitoe A, Cunningham AB, Angelsen A, et al. Managing the Miombo woodlands of Southern Africa: policies, incentives and options for the rural poor. Journal of Natural Resources Policy Research, 2010;2(1):57-73.

Enosse C, Pangaya F, Nhambirre G. Estudo sócio econômico da área da Malonda TreeFarm Distrito de Sanga, Posto administrativo de Unango. Lichinga; 2009.

Falcão MP. Política agrícola e política Agrária: experiência Moçambicana. In: Almeida J, organizador. Políticas Públicas e Desenvolvimento Rural: percepções e perspectivas no Brasil e Moçambique. Porto Alegre: UFRGS; 2009.

Frost P. The ecology of Miombo woodlands. In: Campbell $\mathrm{B}$, editor. The Miombo in transition: woodland and welfare in Africa. Bogor, Indonesia: CIFOR; 1996.

Garlipp R, Foelkel C. O papel das florestas plantadas para atendimento das demandas futuras da sociedade. In: Anais do XIII Congresso Florestal Mundial/FAO; 2009; Buenos Aires. Buenos Aires: Sociedade Brasileira de Silvicultura; 2009. p. 1-18. [citado em 2012 maio 22]. Disponível em: http://www.sbs.org.br/destaques_POSITIONPAPER.pdf

Gauslaa Y. Management and regeneration of tropical woodlands with special reference to Tanzanian conditions: a literature review. Lidia 1989; 2:37-112.

Gil AC. Como elaborar projectos de pesquisa. 4. ed. São Paulo: Atlas; 2007.

Landry, J. Analysis of the potential socio-economic impact of establishing plantation forestry on rural communities in Sanga District, Niassa province, Mozambique [Dissertação]. Cidade do Cabo: Universidade de Stellenbosch; 2009.

Marzoli A. Inventário florestal nacional: avaliação integrada da floresta em Moçambique (AIFM). Maputo: Direção Nacional de Terras e Florestas; 2007.
Moçambique. Ministério da Planificação e Desenvolvimento. Direcção Nacional de Estudos e Análise de Políticas. Pobreza e o bem estar em Moçambique: terceira avaliação nacional. Maputo: Ministério da Planificação e Desenvolvimento; 2010.

Organization for Refuge, Asylum \& Migration - ORAM. Documento de Apresentação na Reunião Nacional sobre Delimitação de Terras Comunitárias. Maputo: ORAM; 2010.

Programa das Nações Unidas para o Desenvolvimento PNUD. Indicadores rápidos de Moçambique: unidade de análises de políticas e economia [online]. Brasília: PNUD; 2012 [citado em 2012 out. 2]. Disponível em: http//:www. undp.org.mz/.../Indicadores\%20Rápidos\%20de\%

Rea L, Parker R. Designing and conducting survey reserch: a comprehensive guide. San Francisco: Jossey-Bass Publishers; 1997.

Ribeiro NS, Shugart HH, Swap RJ, Okin GS. Five-years period of fire regime in the Miombo woodlands of Niassa Reserve, Mozambique. International Journal of Wildland Fire; 2008:101-133.

Salomão A, Matose F. Towards community based forest management of miombo woodlands in Mozambique [online]. Bogor: CIFOR; 2007. [citado em 2012 mar. 22]. Disponível em: http//www.cifor.org/miombo/docs/ CBNRMMozambique1207.Pdf

Serra C jr, Chicue. J. Lei de Florestas e Fauna Bravia Comentada. Maputo: Centro de Formação Jurídica e Judiciária; 2005.

Sitoe A, Salomão A, Wertz-Kanounnikoff S. O contexto de REDD+em Moçambique: causas, actores e instituições. Bogor: CIFOR; 2012. Publicação Ocasional n. 76.

van Bodegom, AJ, van den Berg J, van der Meer P. Forests plantations for sustainable production in the tropics: key issues for decision-makers. Wageningen International, 2008:1-11.

White F. The vegetation of Africa. Place de Fontenoy: UNESCO; 1983. 